is no evidence that extraneuronal catecholamines are stored in this type of amine granules, disappearance of extraneuronal fluorescence after reserpine cannot be used to test the specificity.

Department of Histology,

Clates Wirsén Bertil Hamberger

Karolinska Institutet,

Stockholm 60,

Sweden.

'Dawkins, M. J. R., Duckett, S., and Pearse, A. G. E., Nature, 209, 1144 (1966).

' Falck, B., Hillarp, N.-A., Thieme, G., and Torp, A., J. Histochem. Cytochem., 10, 348 (1962).

a Corrodi, H., and Hillarp, N.-A., Helv. Chim. Acta, 46, 2425 (1963); ibid.,

+ Wirsén, C., Nature, 202,913 (1964).

Hamberger, B., Malmfors, T., and Sachs, C., J. Histochem. Cytochem., 13 147 (1965).

- Hamberger, B., and Masuoka, D., Acta Pharmacol.,22, 363 (1965).

'Wirsén, C., Acta Physiol. Scand., 65, suppl. 252 (1965).

Norberg, K.-A., and Hamberger, B., Acta Physiol. Scand., 68, suppl. 238 (1964).

'Stock, K., and Westermann, E. O., J. Lipid Res., 4, 297 (1963).

${ }^{10}$ Andén, N.-E., Norberg, K.-A., and Olson, L., Acta Physiol. Scand., 66, 501 (1966).

${ }^{11}$ Corrodi, H., Hillarp, N.-A., and Jonsson, G., J. Histochem. Cytochem., 12 $582(1964)$.

12 Carlsson, A., Hillarp, N.-A., and Waldeck, B., Acta Physiol. Scand., 59, suppl. $215(1963)$; Euler, U. S. von, and Lishajko, F., Intern. J Neuro. pharmacol., 2, 127 (1963).

\section{Fibrinolytic Activity of some Biarylcarboxylic Acids}

BUFFERED solutions of certain aromatic acids dissolve human plasma clots when incubated with them in vitro ${ }^{1,2}$. The most active in this respect have proved to be arylcarboxylates, which possess an additional free rotating phenyl ring, for example, $N$-phenylanthranilates ${ }^{3}$, 5benzyloxysalicylates ${ }^{4}$ and diphenylethylacetate ${ }^{5}$. It was suggested that non-condensed aryl rings in the presence of an acidic functional group are required to render a highly active fibrinolytic agent ${ }^{5}$.

To check this suggestion we tested for fibrinolytic activity the twenty-two biarylcarboxylates presented in Table 1. The standard clots of recalcified human plasma were incubated for $18 \mathrm{~h}$ at $37^{\circ} \mathrm{C}$ and immersed in trisbuffered solutions of sodium salts of the compounds being investigated. The range of concentrations investigated was 1-100 mmoles/l. Solutions more alkaline than $p$ H $8 \cdot 0$ were rejected. Details of procedure have been described by von Kaulla ${ }^{6}$ and in a previous paper 5 .

The results are presented in Table 1 . It can be seen that simple diphenylcarboxylic acids (No. 4 and No. 5) are inactive, but when the carboxylic group is attached to the ring through an alkyl or alkylene chain (No. 1 and No. 2) but not through an alkoxy chain (No. 3) there is rather high fibrinolytic activity.

Compounds with both phenyl rings bridged through the oxygen atom (No. 6 and No. 7) are inactive, but if instead of oxygen the - NH- group is inserted $N$-phenylanthranilates can be obtained and these compounds are active fibrinolytics ${ }^{3}$. Here are presented only the most active compounds (No. 8, No. 9 and No. 10). Compound No. 11 is given as an example of the undesirable effect of hydroxylation on the fibrinolytic activity of $N$-phenylanthranilic acid.

If a one carbon atom group represents the bridge be. tween two phenyl rings the fibrinolytic activity is observed only when the functional carboxylic group is attached directly to this methylene bridge (No. 14), but not to the phenyl ring (No. 12 and No. 13). Any further substitution of the methylene bridge is undesirable (No. 15 and No. 16) especially when the heavy chlorine atom is introduced (No. 16).

Diphenylethane 0. carboxylate derivatives (No. 17 and No. 18) are active, but the translocation of the carboxylic group from the ring into an alkoxy side chain abolishes
Table 1. FLBRINOLYTIC ACTIVITY OF SOMT BIARYLCARBOXYYTC AOIDS

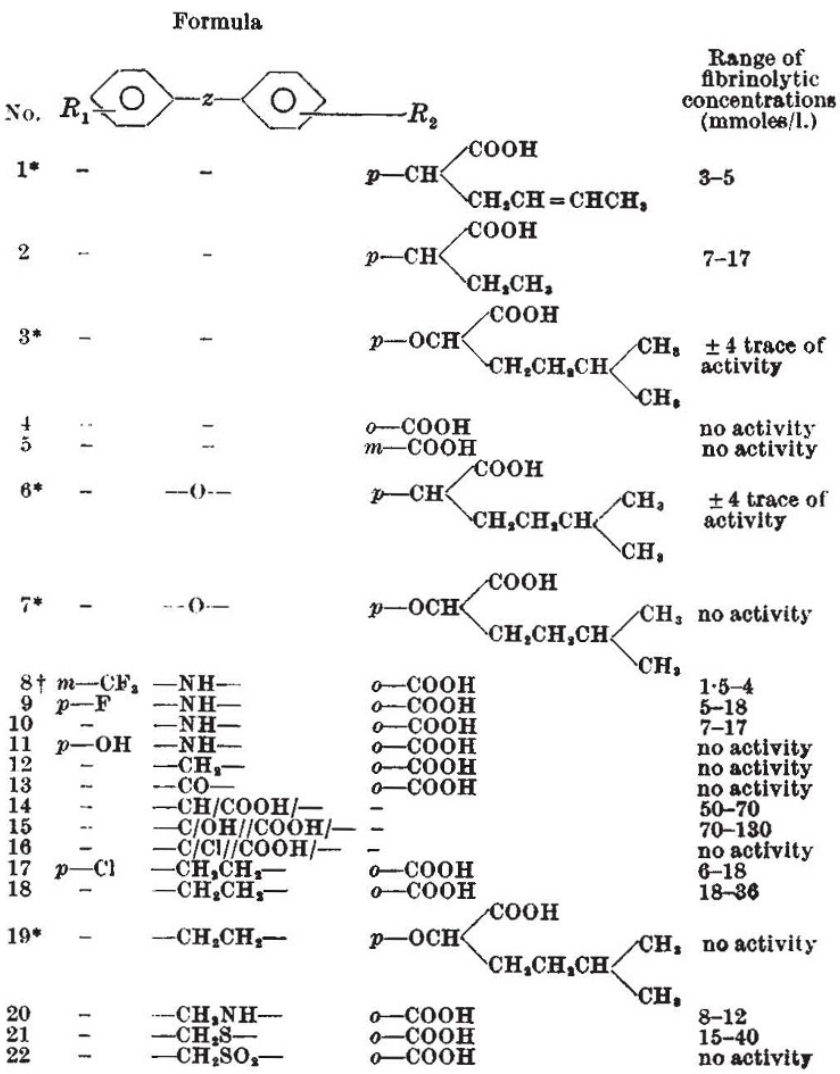

- These compounds supplied by Dr. F. Barzaghi of the Vister Pharmacological Laburatory, Italy.

† This compound was supplied by Dr. R. A. Scherrer from Parke Davis

the fibrinolytic activity (No. 19) in a similar fashion to that in compounds No. 3 and No. 7.

In the molecule of diphenylethane-o-carboxylic acid the ethylene bridge has been changed for isosteric $-\mathrm{CH}_{2} \mathrm{NH}-$ or $-\mathrm{CH}_{2} \mathrm{~S}-$ groups. Compounds thus obtained (No. 20 and No. 21) are slightly more active than the parent structure (No. 18); however, diphenylmethylsulphonyl0 -carboxylic acid (No. 22) is inactive.

In summary, the chemical structure of biarylcarboxylic acids cannot be considered as the general requirement to render a highly active fibrinolytic agent, because 2 -arylsubstituted benzoic acids like phenoxy-, benzoyl-, benzylsulphonyl- and benzyl- derivatives as well as diphenylcarboxylic acids themselves do not dissolve plasma clots. It should, however, be emphasized that phenylamino-, $\beta$-phenylethyl-, benzylamino-, benzyloxy- and benzylthioderivatives are the most active synthetic fibrinolytics so far known. The further substitution within the ring of an active biphenylcarboxylate structure may potentiate or abolish fibrinolytic activity depending on the substituent used.

\section{R. J. GrXglewski}

M. ECKSTEIN

Department of Pharmacology, and

Department of Pharmaceutical Chemistry,

Medical School in Cracow,

Cracow, Poland.

${ }^{1}$ von Kaulla, K. N., Arzneimittel Forsch., 15, 246 (1965).

${ }^{2}$ von Kaulla, K. N., Thromb. Diath. Haem., 7, 404 (1962)

${ }^{3}$ Gryglewski, R. J., and Gryglewska, T., Biochem. Pharmacol., 15, 1171 (1966).

4 von Kaulla, K. N., Experientia, 21, 439 (1965).

' Gryglewski, R. J., Folia Biol., 14, 3 (1966).

'von Kaulla, K. N., J. Med. Chem., 8, 164 (1965). 